\title{
Interim Report of the SHEA Quality Indicator Study $G$ roup to Be Published
}

Both the SHEA and APIC Boards formally have approved publishing the Interim Report of the Quality Indicator Study Group of SHEA, APIC, and SIS, which was submitted to them by Dr. William E. Scheckler, Chair of the study group, in December 1993. This interim report will be published in the societies' journals in the next few months and contains an outline of the issues important for outcome indicators in general and nosocomial infection outcome indicators in particular. The importance of such indicators is becoming clear as the health reform debate talks more about "report cards" for healthcare alliances to use as they judge healthcare providers-both physicians and hospitals.

William E. Scheckler, MD, would be happy to hear from any SHEA members with concerns or thoughts about the activities of the
Study Group and the issues raised by quality indicators. You may reach him at the University of Wisconsin Department of Family Medicine, 777 South Mills St., Madison, WI 53715. Telephone (608) 263-3637; FAX (608) 263-5813; E. Mail wes(afammed. wisc.edu.

Brief items of interest for the SHEA N ews or N ewsletter may be sent to C. Glen Mayhall, M D, SHEA, N ewsletter Editor, Division of Infectious D iseases, Route 1092; The Former Shriner's Burns BIdg, R oom 2-64B; U niversity of Texas M edical Branch; Galveston, TX, 77555-1092; FAX (409) 772-6527. Copy should be typed, double-spaced, and should mot exceed five pages. 